NASA/TM-1999-208791

\title{
Improving the Unsteady Aerodynamic Performance of Transonic Turbines Using Neural Networks
}

Man Mohan Rai, Nateri K. Madavan, and Frank W. Huber 
Since its founding, NASA has been dedicated to the advancement of aeronautics and space science. The NASA Scientific and Technical Information (STI) Program Office plays a key part in helping NASA maintain this important role.

The NASA STI Program Office is operated by Langley Research Center, the Lead Center for NASA's scientific and technical information. The NASA STI Program Office provides access to the NASA STI Database, the largest collection of aeronautical and space science STI in the world. The Program Office is also NASA's institutional mechanism for disseminating the results of its research and development activities. These results are published by NASA in the NASA STI Report Series, which includes the following report types:

- TECHNICAL PUBLICATION. Reports of completed research or a major significant phase of research that present the results of NASA programs and include extensive data or theoretical analysis. Includes compilations of significant scientific and technical data and information deemed to be of continuing reference value. NASA's counterpart of peer-reviewed formal professional papers but has less stringent limitations on manuscript length and extent of graphic presentations.

- TECHNICAL MEMORANDUM. Scientific and technical findings that are preliminary or of specialized interest, e.g., quick release reports, working papers, and bibliographies that contain minimal annotation. Does not contain extensive analysis.

- CONTRACTOR REPORT. Scientific and technical findings by NASA-sponsored contractors and grantees.
- CONFERENCE PUBLICATION. Collected papers from scientific and technical conferences, symposia, seminars, or other meetings sponsored or cosponsored by NASA.

- SPECIAL PUBLICATION. Scientific, technical, or historical information from NASA programs, projects, and missions, often concerned with subjects having substantial public interest.

- TECHNICAL TRANSLATION. Englishlanguage translations of foreign scientific and technical material pertinent to NASA's mission.

Specialized services that complement the STI Program Office's diverse offerings include creating custom thesauri, building customized databases, organizing and publishing research results ... even providing videos.

For more information about the NASA STI

Program Office, see the following:

- Access the NASA STI Program Home Page at http://www.sti.nasa.gov

- E-mail your question via the Internet to help@sti.nasa.gov

- Fax your question to the NASA Access Help Desk at (301) 621-0134

- Telephone the NASA Access Help Desk at (301) 621-0390

- Write to: NASA Access Help Desk NASA Center for AeroSpace Information 7121 Standard Drive Hanover, MD 21076-1320 
NASA/TM-1999-208791

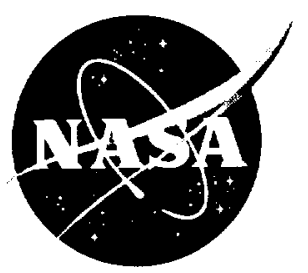

\section{Improving the Unsteady Aerodynamic Performance of Transonic Turbines Using Neural Networks}

Man Mohan Rai and Nateri K. Madavan

Ames Research Center, Moffett Field, California

Frank W. Huber

Riverbend Design Services, Palm Beach Gardens, Florida

National Aeronautics and

Space Administration

Ames Research Center

Moffett Field, California 94035-1000 


\section{Acknowledgments}

The authors would like to thank Dr. R. A. Delaney of Rolls-Royce Allison for permission to use the flow conditions and pressure distributions as guidelines in establishing the reference design used in this investigation.

Available from:

NASA Center for AeroSpace Information 7121 Standard Drive

Hanover, MD 21076-1320

(301) 621-0390
National Technical Information Service 5285 Port Royal Road Springfield, VA 22161 (703) 487-4650 


\title{
Improving the Unsteady Aerodynamic Performance of Transonic Turbines Using Neural Networks
}

\author{
Man Mohan Rai, Nateri K. Madavan, and Frank W. Huber ${ }^{*}$ \\ Ames Research Center
}

\section{Summary}

A recently developed neural net-based aerodynamic design procedure is used in the redesign of a transonic turbine stage to improve its unsteady aerodynamic performance. The redesign procedure used incorporates the advantages of both traditional response surface methodology (RSM) and neural networks by employing a strategy called parameter-based partitioning of the design space. Starting from the reference design, a sequence of response surfaces based on both neural networks and polynomial fits are constructed to traverse the design space in search of an optimal solution that exhibits improved unsteady performance. The procedure combines the power of neural networks and the economy of low-order polynomials (in terms of number of simulations required and network training requirements). A time-accurate, two-dimensional, Navier-Stokes solver is used to evaluate the various intermediate designs and provide inputs to the optimization procedure. The procedure yielded a modified design that improves the aerodynamic performance through small changes to the reference design geometry. These results demonstrate the capabilities of the neural net-based design procedure, and also show the advantages of including high-fidelity unsteady simulations that capture the relevant flow physics in the design optimization process.

\footnotetext{
A patent application that covers some of the original ideas in this repor has been filed by NASA. This report has been submitted for review toward presentation at the 38th AlAA Acrospace Sciences Meeting and Exhibit. Jan. 10-13, 2000. Reno, NV.

*Riverbend Design Services, Palm Beach Gardens, Florida.
}

\section{Introduction}

Modern high pressure (HP) turbines are usually composed of either one or two stages. Two-stage turbines are longer and heavier but are subsonic and usually more efficient. Single-stage turbines are lighter and compact but operate in the transonic regime and suffer efficiency penalties due to shock losses and high loadings (ref. 1). The aerodynamic design of transonic HP aircraft engine turbines is complicated by the presence of shocks, wakes, tip leakage and other secondary flow effects in the flow field. These shocks, wakes, and vortical flows are ingested by downstream stages resulting in complex interactions within and between the stages. All of these effects are complicated further by the inherent unsteadiness of the flow field that results from the relative motion of the rotor and stator rows and gives rise to unsteady interactions both within the HP turbine stages and between the HP turbine and the adjacent low pressure (LP) turbine stages. These unsteady interactions may be large enough to affect the time-averaged features of the flow. Designers have to pay special attention to shocks in transonic turbines because of their detrimental effects, such as poor aerodynamic performance, unsteady stresses, vibration, and reduced blade life. A design optimization method that helps the designers in their efforts to mitigate the effects of these shocks would serve as a useful tool.

Several experimental investigations of transonic turbines aimed at characterizing shock formation (ref. 2), unsteady stage interactions (ref. 3). heat transfer effects (ref. 4), and other physical flow phenomena have been performed over the years. Various numerical investigations of these flow fields ranging from single blade row computations to time-accurate Navier-Stokes computations in two dimensions (ref. 5, 6,7) and more recently in three dimensions (ref. 1,8 ) have also added to our 
understanding of these flows. Typically, weak oblique shocks occur at the stator and rotor airfoil trailing edges. The stator airfoil shock interacts with the other stator and rotor airfoils to set up a complex pattern of direct and reflected shock waves within the stage (ref. 5, 6). The rotor airfoil trailing edge shock on the other hand interacts with the downstream LP stage. The efficiency penalties resulting from these shocks can be quite large. For example, Giles (ref. 5) notes that the unsteady shocks result in a $40 \%$ variation in the lift on the rotor, resulting in structural vibrations, increased losses. and temporary leading edge boundary layer separation on the rotor suction surface. Jennions and Adamczyk (ref. 1) report a turbine design where it was speculated that a $5.6 \%$ loss in efficiency was due largely to the HP rotor shock interactions with the LP turbine stator airfoils.

The main objective of this paper is to demonstrate that a systematic application of an aerodynamic design optimization method to a transonic turbine can enhance the turbine's unsteady aerodynamic performance without changing its size or reducing its efficiency and work output. A variety of formal optimization methods have been developed in the past and applied to turbine design. Some of these methods are reviewed in our earlier work (ref. 9).

More recently, the authors have developed a different approach to turbomachinery airfoil design optimization that is based on neural networks (ref. 10 . 11). This method offers several advantages over traditional optimization procedures. First, neural networks are particularly suitable for multidimensional interpolation of data that lack structure. They can provide a greater level of flexibility than other methods in dealing with design in the context of unsteady flows, partial and complete datasets, combined experimental and numerical data, the need to include various constraints and rules of thumb, and other features that characterize the aerodynamic design process. Second, neural networks provide a natural framework within which a succession of numerical solutions of increasing fidelity can be used in the optimization process. Here the term fidelity is used to denote the extent to which the system of equations faithfully represents the physical characteristics of the flow. Third, and perhaps most important, neural networks offer an excellent framework for multidisciplinary design optimization. Simulation tools from various disciplines can be integrated within this framework. Efficient use can also be made of parallel computing resources. Rapid trade-off studies across one or many disciplines can also be performed.

Madavan et al. (ref. 9) have applied a neural netbased method (ref. 10,11) to the redesign of a gas generator turbine with the goal of improving its unsteady aerodynamic performance. The turbine chosen was the first stage of a two-stage configuration characterized by high turning angles and high specific work per stage (ref. 12). Although the turbine was designed to operate in the high-subsonic regime, an unsteady analysis showed very strong interaction effects including an unsteady shock in the axial gap region between the stator and rotor rows. The authors' goal in this effort was to reduce the strength of this shock by optimizing the airfoil geometries thereby improving the unsteady aerodynamic performance of the turbine. Since the shock could only be discerned by an unsteady aerodynamic analysis, a time-accurate NavierStokes solver (ref. 13) was coupled to the neural net-based optimizer. The neural net-based optimization method yielded a modified design that was very close to the reference design and achieved the same efficiency and work output but eliminated the shock and thus exhibited better unsteady aerodynamic performance.

This paper deals with the application of the design optimization method of Rai and Madavan (ref. 11) to the redesign of a transonic turbine stage. The design goal is to improve its unsteady aerodynamic performance by weakening the shocks in the stage and thus reducing their effect on turbine aerodynamics. As in Madavan et al. (ref. 9) the tangential force on the rotor is constrained so that it does not decrease during the optimization process. Details regarding the redesign procedure and the results obtained are discussed in the following sections

\section{The Reference Design}

The single-stage turbine geometry that is considered for redesign in this study is based on the transonic turbine investigated in Rao and 
Delaney (ref. 14) and Dunn et al. (ref. 15). The time-averaged surface pressure distributions on the stator and rotor airfoils obtained using a NavierStokes solution procedure are presented in Rao and Delaney (ref. 14). These pressure distributions were used to design the stator and rotor airfoils employed in this study. The method of Rai and Madavan (ref. 11) was used in an inverse design mode to generate the airfoil shapes. Although this method could have yielded a very accurate description of the original rotor and stator airfoils (ref. 14 . 15) no attempt was made to reproduce these airfoils. Instead, the airfoils in this study were designed to have pressure distributions that exhibit the main features of the pressure distributions in Rao and Delaney (ref. 14). Table 1 lists all the relevant flow and geometry parameters for the current turbine geometry. The flow conditions, like the geometry, are close, but not identical, to those of Rao and Delaney (ref. 14) and Dunn et al. (ref. 15). The radius of the trailing edge circle and the axial chord for both the stator and rotor airfoils were not changed during the redesign process. The axial gap between the stator and rotor rows was also left unchanged.

\section{The Design Procedure}

In this paper we use our neural net-based turbomachinery airfoil design procedure to improve the reference design by successfully mitigating the effects of the unsteady shocks. We accomplish our redesign objective by optimizing the shape of the airfoils. Our purpose is to demonstrate the capabilities of our method for design in an unsteady flow environment and also to show the advantages of capturing the relevant flow physics using high-fidelity unsteady simulations in the optimization process.

\section{Airfoil Geometry Parameterization}

Geometry parameterization and prudent selection of design variables are among the most critical aspects of any shape optimization procedure. Since this study focuses on airfoil redesign, the ability to represent various airfoil geometries with a common set of geometrical parameters is essential. Variations of the airfoil geometry can be obtained

\begin{tabular}{|l|l|}
\hline Parameter & $\begin{array}{l}\text { Reference } \\
\text { Design }\end{array}$ \\
\hline Number of stator airfoils & 30 \\
\hline Number of rotor airfoils & 45 \\
\hline Midspan radius (in.) & 9.680 \\
\hline Axial gap (in.) & 0.600 \\
\hline $\begin{array}{l}\text { Stator trailing edge circle radius } \\
\text { (in.) }\end{array}$ & 0.020 \\
\hline $\begin{array}{l}\text { Rotor trailing edge circle radius } \\
\text { (in.) }\end{array}$ & 0.020 \\
\hline Stator axial chord (in.) & 1.442 \\
\hline Rotor axial chord (in.) & 1.570 \\
\hline Pressure ratio across stage & 0.25 \\
\hline $\begin{array}{l}\text { Stator inflow temperature } \\
\text { Unit Reynolds number at stator } \\
\text { inlet (per inch) }\end{array}$ & $950^{\circ} \mathrm{R}$ \\
\hline $\begin{array}{l}\text { Flow coefficient (stator inlet veloc- } \\
\text { ity/wheel speed }\end{array}$ & $3.0 \times 10^{5}$ \\
\hline Ratio of specific heats & 0.2165 \\
\hline Stator inflow angle & 1.4 \\
\hline Stator outflow angle & $0.0^{\circ}$ \\
\hline Stator inflow Mach number & $-74.19^{\circ}$ \\
\hline Stator outflow Mach number & 0.15 \\
\hline Rotor-relative inflow angle & 1.124 \\
\hline $\begin{array}{l}\text { Rotor-relative outflow angle } \\
\text { Rotor-relative inflow Mach number } \\
\text { Rotor-relative outtow Mach num- } \\
\text { ber }\end{array}$ & 0.44 \\
\hline
\end{tabular}

TABLE 1. Geometry and flow parameters for the reference design. All angles are measured from the axial direction.

then by smoothly varying these parameters. Geometrical constraints imposed for various reasons, structural, aerodynamic (e.g., to eliminate flow separation), etc., should be included in this parametric representation as much as possible. Additionally, the smallest number of parameters should be used to represent the family of airfoils.

The method used for parameterization of the airfoil geometries is described in Rai and Madavan (ref. 11) and is reviewed here for completeness. 


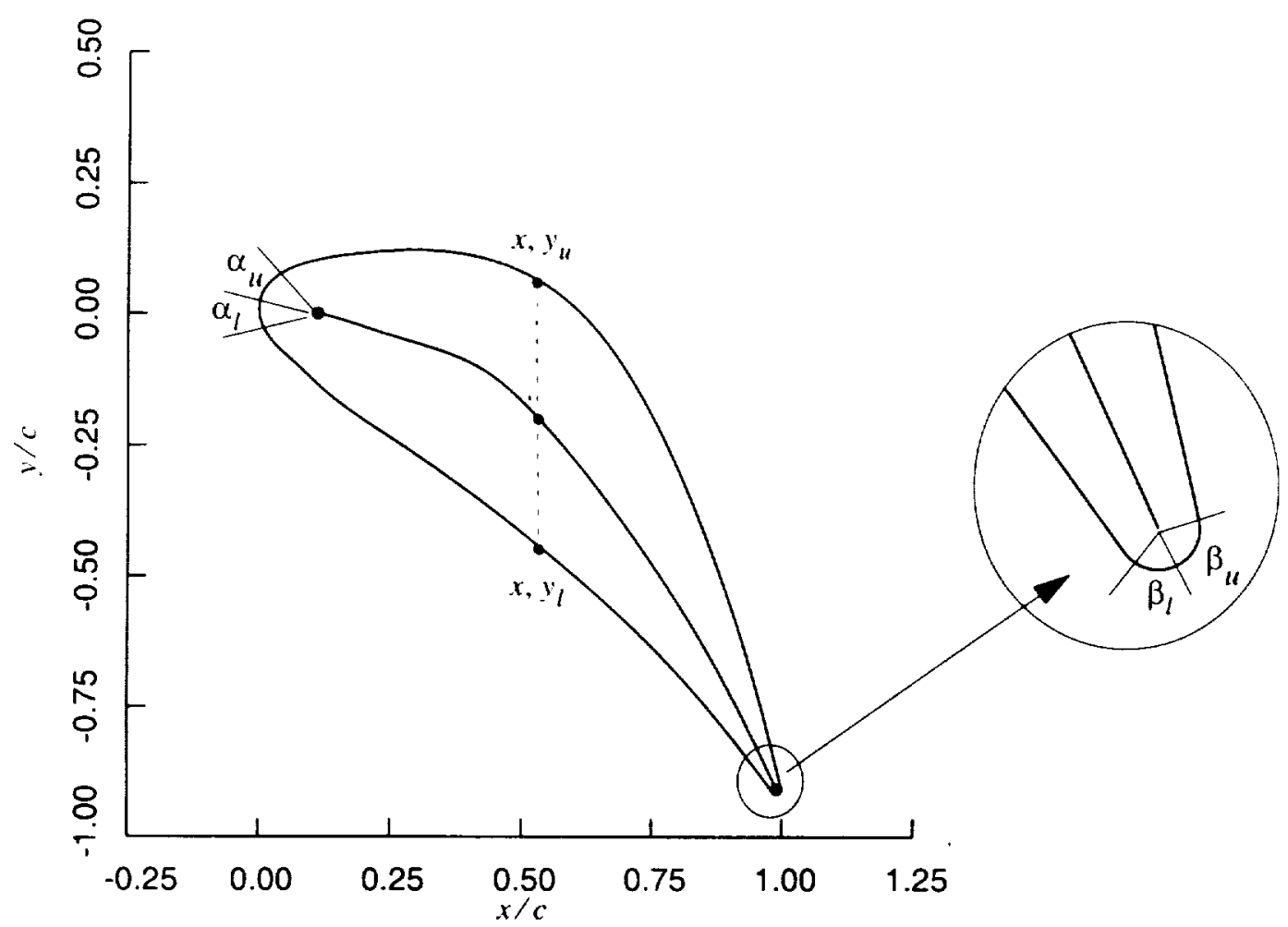

Figure 1. Schematic of a generic airfoil showing location of control points on the airfoil surface and the defining angles used in the parameterization of the airfoil geometry.

Figure 1 illustrates the method for a generic airfoil. Some salient features of the method are noted:

1. The leading edge is constructed using two different ellipses, one for the upper surface and one for the lower surface. The eccentricity of the upper ellipse and the semi-minor axes of both ellipses are specified as geometric parameters $\left(e_{u}, t_{u}\right.$, and $\left.t_{l}\right)$. All other related parameters can be determined analytically. The major axes of both ellipses are aligned with the tangent to the camber line at the leading edge. This tangent is initially aligned with the inlet flow but is allowed to rotate as the design proceeds. The angles $\alpha_{u}$ and $\alpha_{1}$ determine the extent of the region in which the leading edge is determined by these ellipses. The two ellipses meet in a slope-continuous manner.

2. The trailing edge can also be constructed in a similar manner with the major axes of the ellipses aligned with the tangent to the camber line at the trailing edge. However, in this study the trailing edge was defined using a single cir- cle. The angles $\beta_{u}$ and $\beta_{l}$ determine the extent of the region in which the trailing edge is determined by this circle.

3. The region of the upper surface between the upper leading edge ellipse and the trailing edge circle is defined using a tension spline. This tension spline meets the leading edge ellipse and the trailing edge circle in a slope-continuous manner. Additional control points for the tension spline that are equispaced in the axial direction are introduced as necessary. These points provide additional control over the shape of the upper surface. The lower surface of the airfoil between the lower leading edge ellipse and the trailing edge circle is obtained in a similar manner.

A total of 12 geometric parameters were used to define the stator airfoil geometries in the current study. These parameters are listed below:

1. Leading edge and trailing edge airfoil metal angles ( 2 parameters). 
2. Eccentricity of upper leading edge ellipse (1 parameter).

3. Angles defining the extent of the leading edge ellipses (2 parameters).

4. Semi-minor axes values at the leading edge (2 parameters).

5. Angles defining the extent of the trailing edge circle (2 parameters).

6. Airfoil $y$-coordinate values (see fig. 1) at midchord on the upper and lower surfaces ( 2 parameters).

\section{Airfoil stagger angle ( 1 parameter).}

Since the rotor airfoil geometries are somewhat more complicated than the stator airfoil, two additional parameters were required to represent the airfoils. These parameters were the airfoil $y$-coordinate values at two additional points on the suction surface of the airfoil. An accurate representation of the stator and rotor airfoils in the reference design was obtained using these 12 and 14 parameters, respectively. Acceptable modified airfoil shapes required by the optimization procedure were obtained easily by varying some or all of these parameters.

\section{Unsteady Aerodynamic Analysis}

Unsteady aerodynamic analyses of the turbine stage configurations required during the redesign process were obtained using the ROTOR-2 computer code (ref. 13). This code solves the unsteady, two-dimensional, thin-layer Navier-Stokes equations for rotor-stator configurations in a time-accurate manner. The computational method used is a third-order-accurate, iterative-implicit, upwindbiased scheme that solves the time-dependent, Reynolds-averaged Navier-Stokes equations. Details regarding the solution methodology can be found in reference 13 .

The flow domain is discretized using a system of patched and overlaid grids; the grids attached to the rotor airfoils can move relative to the grids attached to the stator airfoil to simulate the rotor motion.

Figure 2 shows the stator and rotor airfoil cross sections at midspan for the reference turbine design. The reference design has 30 airfoils in the stator row and 45 in the rotor row. This flow can be simulated by modeling 2 stator airfoils and 3 rotor airfoils as a system.

Figure 2 also shows the grid system used to discretize the flow domain. Each airfoil has two grids associated with it: an inner "O" grid that contains the airfoil and an outer " $\mathrm{H}$ " grid that conforms to the external boundaries. For the analyses performed here, each inner $O$ grid has 151 points in the circumferential direction and 41 points in the wall-normal direction. Each outer $\mathrm{H}$ grid has 101 points in the axial direction and 51 points in the transverse direction. For the sake of clarity, only some of the grid points are shown in figure 2 .

The dependent variables are initialized to freestream values and the equations of motion are then integrated subject to the boundary conditions. The flow parameters that are specified are the pressure ratio across the turbine (ratio of exit static pressure to inlet total pressure), inlet temperature and flow angle, flow coefficient, and unit Reynolds number based on inlet conditions.

\section{Optimization Problem Formulation}

The goal of the redesign effort is to improve the unsteady aerodynamic performance of the turbine by optimizing the shape of the stator and rotor airfoils. This is accomplished by formulating an objective function that minimizes the unsteady amplitudes $\tilde{p}_{i}$ on the stator (or rotor) airfoil subject to the constraint that the tangential force on the rotor airfoil (i.e., turbine work output) does not decrease. The pressure amplitude $\tilde{p}_{i}$ is used as a measure of the unsteadiness in the flow field and is defined as the difference between the maximum and minimum pressures occurring over a complete cycle at each point on the airfoil surface. For the stator airfoil, a cycle corresponds to the motion of the rotor through a distance equal to the rotor pitch. Similarly, for the rotor airfoil, a cycle corresponds to the motion of the rotor through a distance equal to the stator pitch. Thus, the pressure amplitude $\tilde{p}_{i}$ is defined as:

$$
\tilde{p}_{i}=\left(p_{i, \max }-p_{i, \min }\right)_{\text {cycle }}
$$




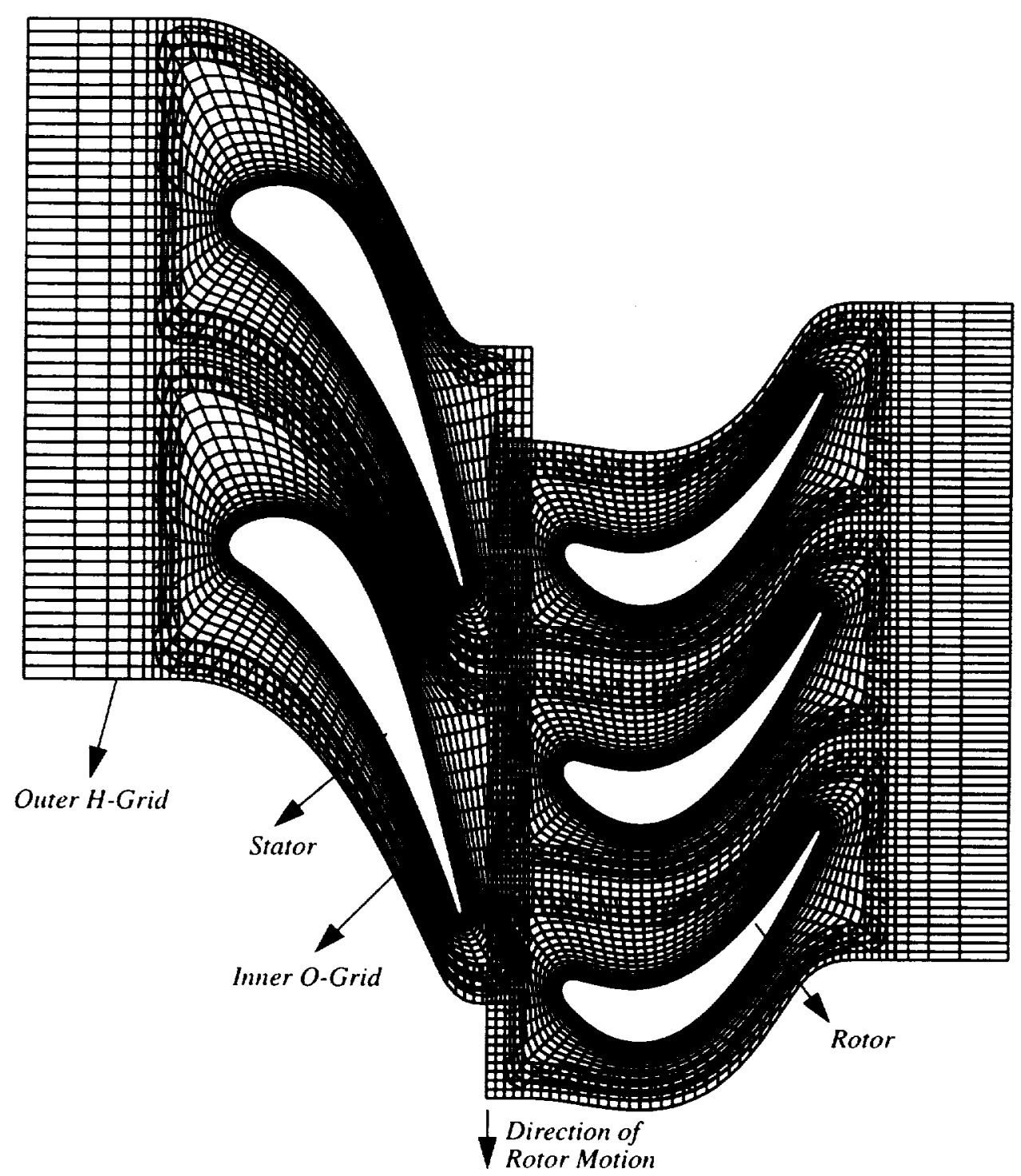

Figure 2. Turbine geometry (at midspan of reference design) and computational grid used.

In the current redesign effort the goal is to improve unsteady aerodynamic performance by weakening the shocks in the turbine stage. The presence of these shocks in the reference design results in large unsteady pressure amplitudes. Thus the pressure amplitudes are directly related to the strengths of these shocks. Hence it is assumed that a reduction in the unsteady amplitudes on the stator (and/or rotor) will result in weakened shocks. The results obtained demonstrate the validity of this assump- tion. The unsteadiness due to potential and wake/ blade interactions between the stator and rotor airfoils will still be present since the axial gap between the stator and airfoil rows is not changed in the optimization process.

\section{Neural Net-Based Design Procedure}

The design procedure used here is that of Rai and Madavan (ref. 11). The procedure uses a sequence 
of response surfaces based on both neural networks and polynomial fits to traverse the design space in search of the optimal solution. A technique called parameter-based partitioning of the design space is used. where the functional dependence of the variables of interest (e.g., pressure) with respect to some of the design parameters is represented using neural networks, and the functional dependence with respect to the remaining parameters is represented using polynomials. The power of neural networks and the economy of low-order polynomials (in terms of number of simulations required and network training requirements) are thus effectively combined. The method (ref. 11) can be viewed as a variant of Response Surface Methodology (ref. 16, 17), or RSM, where the response surfaces are constructed using both neural networks and polynomials. Traditional RSM uses only low-order polynomials in constructing the response surfaces.

The method uses polynomial approximations on multidimensional simplexes. An $s$-dimensional simplex is a spatial configuration of $s$ dimensions determined by $s+1$ equispaced vertices that lie on a hypersphere of unit radius. (By this definition, a two-dimensional simplex is an equilateral triangle that is circumscribed by a unit circle.) This approach assumes that the local variation of the design objective function can be accurately represented using low-order polynomials, which is very often the case. The polynomial fit on this simplex together with the trained neural network represents a composite response surface. The optimization procedure then uses a sequence of such composite response surfaces to traverse through the design space in search of the optimal solution.

Parameter-based partitioning of the design space is accomplished in the following manner. Since the variation of the unsteady pressure amplitudes along the airfoil surfaces is typically far more complicated than the variation with small changes in geometric parameter values, a neural network is used to represent unsteady pressure amplitude variation in physical space. The three-layer neural network (with two hidden layers) shown in figure 3 is used for this purpose. The first node in the input layer is a bias node (input of 1.0). The second set of nodes are used to specify the physical location. Since we are dealing with two-dimensional geometries only, the physical location is specified by a single parameter-the axial location on the airfoil surface. Figure 3 shows a third set of input nodes that are not activated in this study, but may be used in cases where the functional behavior of the pressure amplitudes with some of the geometric parameters is "complex" and one wishes to use the neural network to represent this behavior.

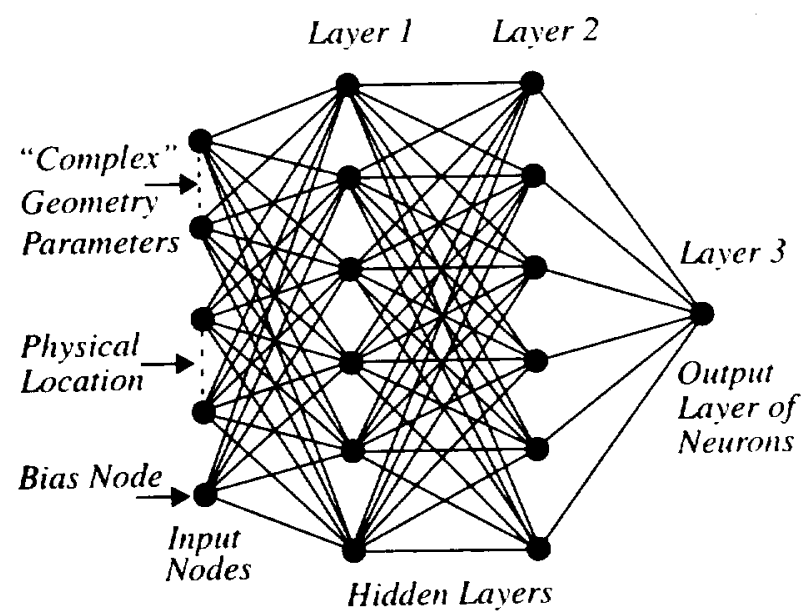

Figure 3. Schematic of the three-layer feedforward neural network used in this study.

The variation of the unsteady pressure amplitudes with the geometry parameters is approximated using simple polynomials. Since a linear variation is assumed, the points at which the pressure amplitude data are determined are located at the vertices of a simplex of dimension equal to the number of geometry parameters.

The optimization strategy used here to redesign the turbine airfoil geometry starting from the reference design can be summarized as follows:

1. Populate the design space in the vicinity of the reference geometry. The reference design geometry serves as the centroid of the first simplex in the optimization process. A simplex in design space is constructed around this centroid and unsteady computational fluid dynamics (CFD) analyses at each of the vertices are obtained. 
2. Train the neural networks and compute the polynomial coefficients to define the composite response surface. The input nodes of the neural nets will typically contain parameters that correspond to the physical location on the airfoil and those geometric parameters that give rise to "complex" surface pressure variations. The neural nets are trained and the polynomial coefficients that define the pressure variation within the simplex are computed. The trained neural networks in combination with the polynomial fit then constitute the composite response surface.

3. Search the region of the design space represented by the composite response surface. A conjugate gradient method was used in this study to perform this constrained search. Geometrical and other constraints can be incorporated within this search procedure easily. In addition, constraints that limit the search procedure to the volume of the simplex are also incorporated in the search.

4. Relocate the simplex. If the local optimum obtained in the previous step lies on the boundaries of the simplex then this point is chosen as the new centroid and steps 1-4 are repeated until the search culminates inside the simplex. However, the process can be stopped at any time when the design is deemed adequate.

5. Validate the design. As a final step in the process an unsteady aerodynamic analysis is carried out for the geometry corresponding to the optimal design to determine the adequacy and quality of the design.

\section{Implementation Details}

The optimization procedure was initiated from the reference design. The process focused initially on the aft portion of the stator airfoil. Although 12 geometric parameters were used to represent the stator airfoil, only 5 of these parameters were considered in order to obtain the modified design. These were the angles defining the extent of the trailing edge circle ( 2 parameters), the airfoil midchord $y$-coordinate values on the upper and lower surfaces ( 2 parameters), and the stagger angle ( 1 parameter). A linear variation of the objective function with respect to the geometric parameters was assumed. resulting in a five-dimensional simplex (with six vertices) at each design optimization step. The process of constructing new simplexes and searching for the local optimum was repeated twice to arrive at the modified design of the stator airfoil. An additional optimization step was then performed where the rotor airfoil was modified. Unlike the stator geometry modification, the process focused on the leading edge of the rotor airfoil. Five parameters that define the rotor leading edge were considered. These parameters were the airfoil thickness values at the leading edge ( 2 parameters), airfoil leading edge metal angle ( 1 parameter), and the angles defining the extent of the leading edge ellipse ( 2 parameters).

Each of the six 3-layer nets (representing the six vertices of the simplex) had two input nodes, one for the bias and one for the axial location, and one output neuron. Both the first and second hidden layers had 15 neurons each for a total of 270 connection weights. Thus, the total number of connection weights for all six nets was 1620. During the training process the training error was reduced by about four orders of magnitude from the initial value.

\section{Results}

The neural net-based design method was used to optimize the unsteady performance of the reference turbine. Both the stator and rotor airfoil geometries were modified in the process. The optimization yielded stator and rotor airfoils that were very similar to the reference airfoils. However, the flow through the optimized turbine stage was found to be much more quiescent and the shocks were weaker. A comparison of the optimized design with the reference design is presented in this section.

\section{Comparison of Airfoil Geometries for Reference and Optimized Designs}

Figures 4 and 5 compare the stator and rotor airfoil geometries for the reference and optimized designs, respectively. The stator airfoil geometries of the reference and optimized designs are very close to each other. The suction surface has been thinned out in the aft region, and the location of the point where the maximum thickness occurs (the 


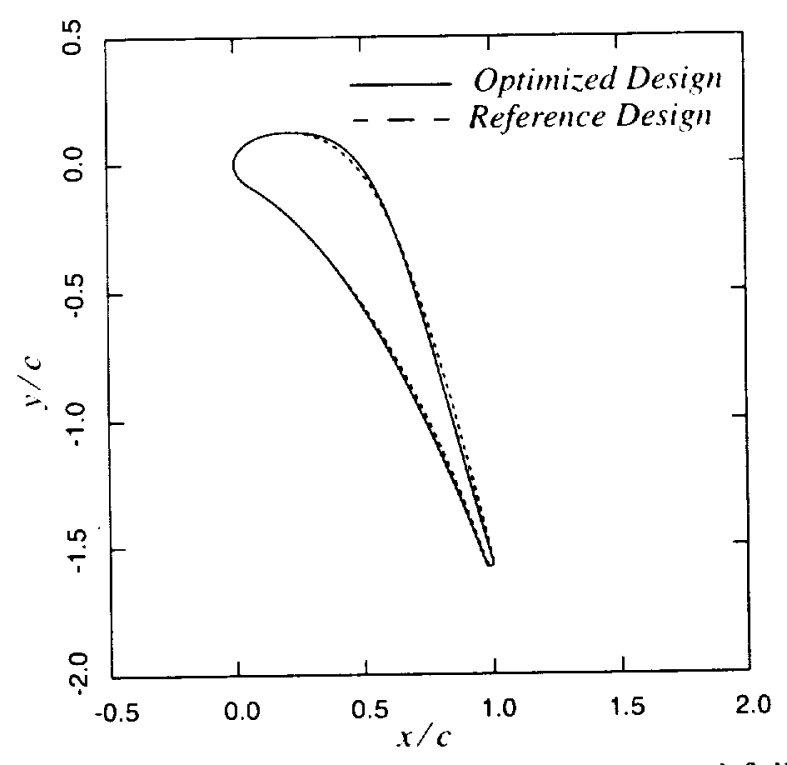

Figure 4. Comparison of the stator airfoil geometries for the reference and optimized designs.

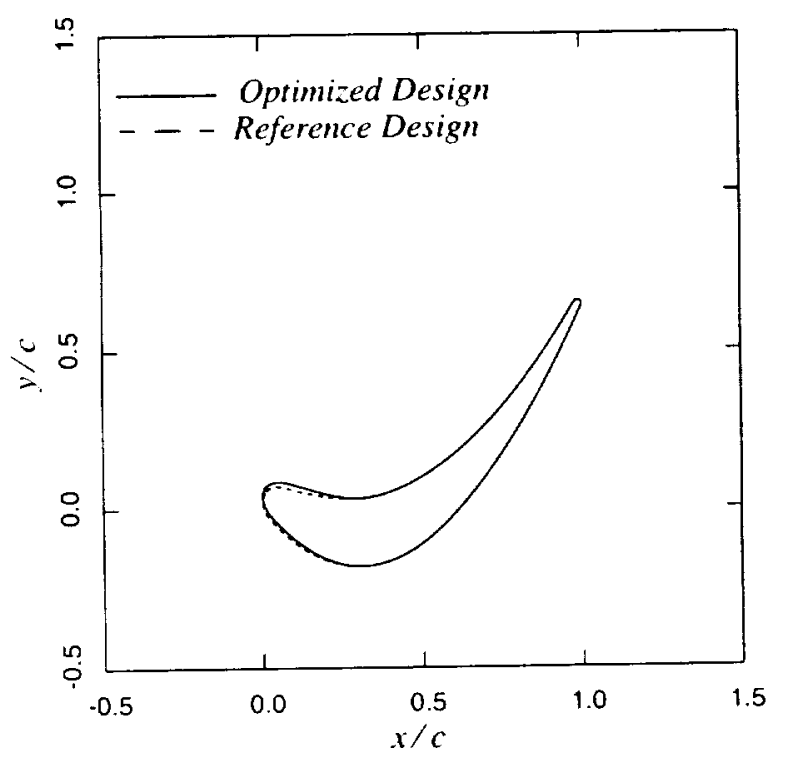

Figure 5. Comparison of the rotor airfoil geometries for the reference and optimized designs. airfoil "crown") has moved away from the leading edge. The rotor airfoil geometries of the reference and optimized designs are also very close to each other. The main differences are confined to the leading edge region of the rotor airfoil. The inlet metal angle of the rotor airfoil has changed slightly. Although the rotor and stator geometry modifications are not significant, their impact on the unsteady flow features in the turbine stage is substantial, as the following results will show.

\section{Static Pressure Variation on Airfoils}

Figure 6 shows the time-averaged static pressure distribution on the stator airfoil. The reference pressure, $p_{t, r e f}$, in this case is the total pressure at the stator inlet. The static pressure is time-averaged over a stator cycle. In the optimized design, the loading in the trailing edge region has decreased and the loading in the mid-chord region has increased. The tangential force on the stator is almost identical for both the reference and optimized designs.

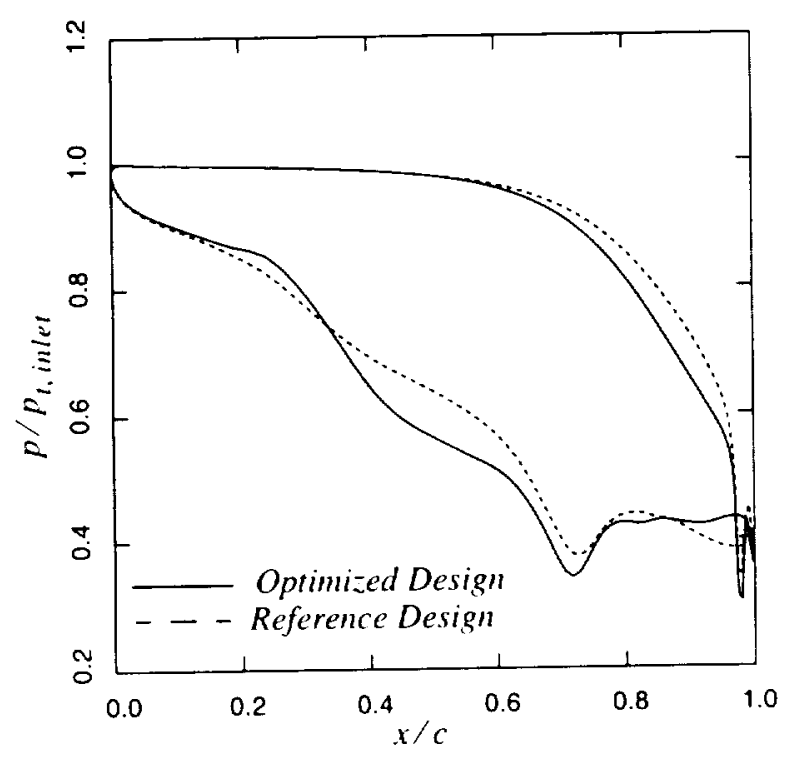

Figure 6. Comparison of the time-averaged pressure distributions on the stator airfoils for the reference and optimized designs. 
The distribution of time-averaged pressures on the rotor airfoils is compared for the reference and optimized designs in figure 7 . The reference pressure, $p_{t, r e f}$, in this case is the total pressure at the inlet to the stator, and the time-averaging is performed over one rotor cycle. In the optimized design, the loading in the leading edge region has been reduced and the loading in the midchord region has increased. As in the case of the stator, the tangential force on the rotor airfoil is almost identical for the reference and optimized designs. This is achieved by imposing the constraint that the tangential force on the rotor airfoil cannot decrease during the optimization process. This constraint was imposed using a penalty function approach.

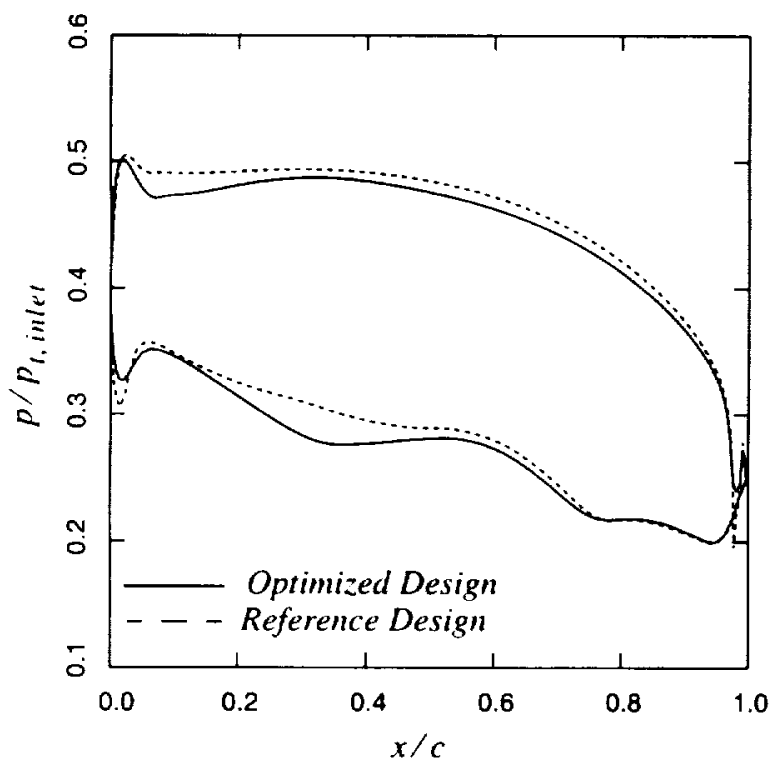

Figure 7. Comparison of the time-averaged pressure distributions on the rotor airfoils for the reference and optimized designs.

A second feature of interest is that for the optimized design the magnitudes of the suction and pressure side overspeeds near the rotor leading edge have been equalized. This balance is a desirable feature that designers seek to achieve in turbine design. It is interesting to note that the optimization process achieves this balance as a matter of course in the context of unsteady flow.

While the original design guideline was based on experience with steady flows, the results obtained here indicate that it may also be applicable to highly unsteady turbine flows. Of course, consideration of any required off-design operating conditions may change the optimum design point distribution of suction and pressure side overspeed.

It is noted here that while off-design operation is an important consideration in the design, the current study focuses only on optimizing the geometry at the design point. The present design method can be used for design optimization in the context of multiple operating points.

The unsteady aerodynamic performance of the first stage of a gas generator turbine was optimized by Madavan et al. (ref. 9). Although the turbine was originally designed to operate in the high-subsonic regime, it showed very strong interaction effects including an unsteady shock in the gap region between the stator and rotor rows. The neural netbased optimization method yielded an optimized design that was very close to the reference design and achieved the same efficiency and work output but eliminated the shock and thus exhibited better unsteady aerodynamic performance.

Although the reference designs and flow parameters for the current turbine and the gas generator turbine (ref. 9) are quite different, there are some similarities in the changes to the designs obtained as a result of the optimization process. In both cases, the latter half of the suction side of the stator is not as curved and the location of the airfoil crown moves away from the leading edge. This results in lowered peak Mach numbers on the suction side very near the trailing edge thus resulting in a weakening of any shock(s) that may be present in this region. Additionally, the loading in the trailing edge region of the stator was reduced and the loading in the midchord region was increased. In both turbines, the loading in the leading edge region of the rotor was reduced. These changes in the geometry and the mean flow substantially reduced the unsteady effects in both cases.

\section{Instantaneous Pressure Contours in the Flow}

Figures 8 through 19 compare the instantaneous pressure contours for the reference and optimized 
designs. In discussing these figures, we will focus on the rotor airfoil marked 3 and the stator passage between stator airfoils marked 1 and 2 . The periodicity boundary condition used in these computations implies that the flow associated with stator 1 is identical to that of stator 3 . Similarly, the flow associated with rotor 1 is identical to that of rotor 4 .

Figures 8 and 10 show instantaneous pressure contours for the reference and optimized designs, respectively, at the time instant $t=0.0$. Both figures show two trailing edge shocks emanating from stator 1 . The upper trailing edge shock crosses the gap region and impinges on the rotor airfoils. The lower shock is weaker than the upper shock. It impinges on the suction surface of the adjacent stator (stator 2) and is then reflected. This phenomenon is not easily discernible in the figure but can be seen when the number of contours is increased substantially. This reflected shock subsequently crosses the axial gap to impinge on the rotor airfoils. The upper trailing edge shock of the optimized design is weaker than that seen in the reference design. This results in lower pressure amplitudes on the rotor surface.

A second phenomenon of interest is the formation of a reflected shock that is caused by the impingement of the upper stator trailing edge shock on the rotor surface. Figures 8, 9, 12, 13, 16, and 17 show the pressure contours in the reference design at different instants in time. Figures $10,11,14,15,18$, and 19 show these contours in the optimized design at the same instants in time. The formation of the reflected shock and its motion is apparent from these figures (as indicated by the solid arrows). It impinges on the stator suction surface and is once again reflected back towards the rotor airfoils. This reflected shock causes large vibratory loads on the stator. From figures 8 through 19 we see that the optimized design generates a much weaker reflected shock than the reference design. This results in lower pressure amplitudes on the stator surface. Figures 9 and 12 show an additional shock (marked by the dotted arrows) that emanates from the vicinity of the trailing edge of stator 1 on the pressure surface and impinges on the suction surface of stator 2 . This shock is only discernible in the reference design and not in the optimized design.

Another feature of interest in figures 8 through 19 is the rotor trailing edge shock. This shock is for the most part unchanged by the optimization process.

\section{Unsteady Pressure Amplitudes on Airfoils}

A quantitative measure of the unsteadiness in the flow can be obtained from the unsteady pressure amplitudes on the surfaces of the stator and rotor airfoils. The pressure amplitudes are defined as the difference between the maximum and minimum pressures occurring over a complete cycle at each point on the airfoil surface (see eqn. 1). The pressure amplitudes on the stator airfoils for the reference and modified designs are shown in figure 20. The abscissa in figure 20 is the axial distance $x$ (normalized by the stator axial chord, $c$ ) along the stator airfoil measured from the leading edge along the suction surface to the trailing edge and then back to the leading edge along the pressure surface. Figure 20 shows very low amplitude values both on the suction and pressure surfaces near the leading edge. This is because the flow is supersonic in the latter half of the stator passage, and the unsteadiness caused by the interaction of the stator and rotor flowfields does not propagate upstream beyond a certain region. It is evident from the figure that the large unsteady interaction effects in the reference design have been reduced substantially in the optimized design. The maximum pressure amplitude that is located near the trailing edge of the stator airfoil has been reduced by about $35 \%$.

The pressure amplitudes on the rotor airfoils for the reference and optimized designs are shown in figure 21 . The abscissa on figure 21 is the axial distance $x$ (normalized by the rotor axial chord, $c$ ) along the rotor airfoil measured from the trailing edge along the suction surface to the leading edge and then back to the trailing edge along the pressure surface. The rotor pressure amplitude reaches a maximum near the leading edge. Unlike the stator pressure amplitude the rotor pressure amplitude shows several undulations. These are caused by the number of shock/rotor interactions that occur. 


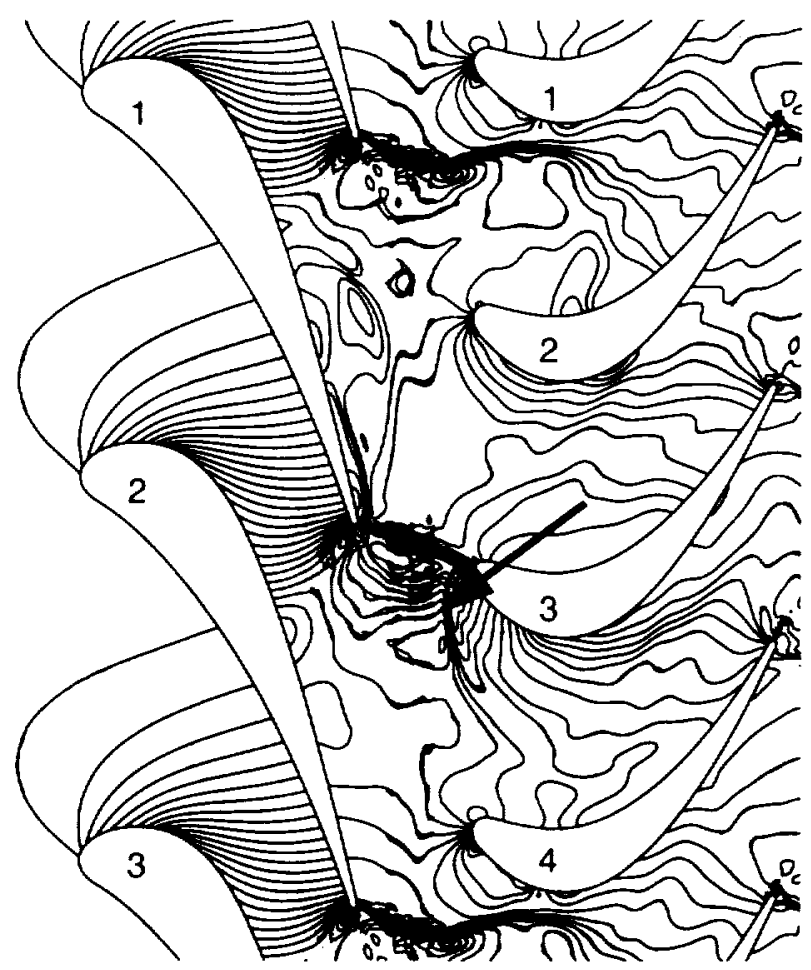

Figure 8. Instantaneous pressure contours in the flow for the reference design at $t=0.0$.

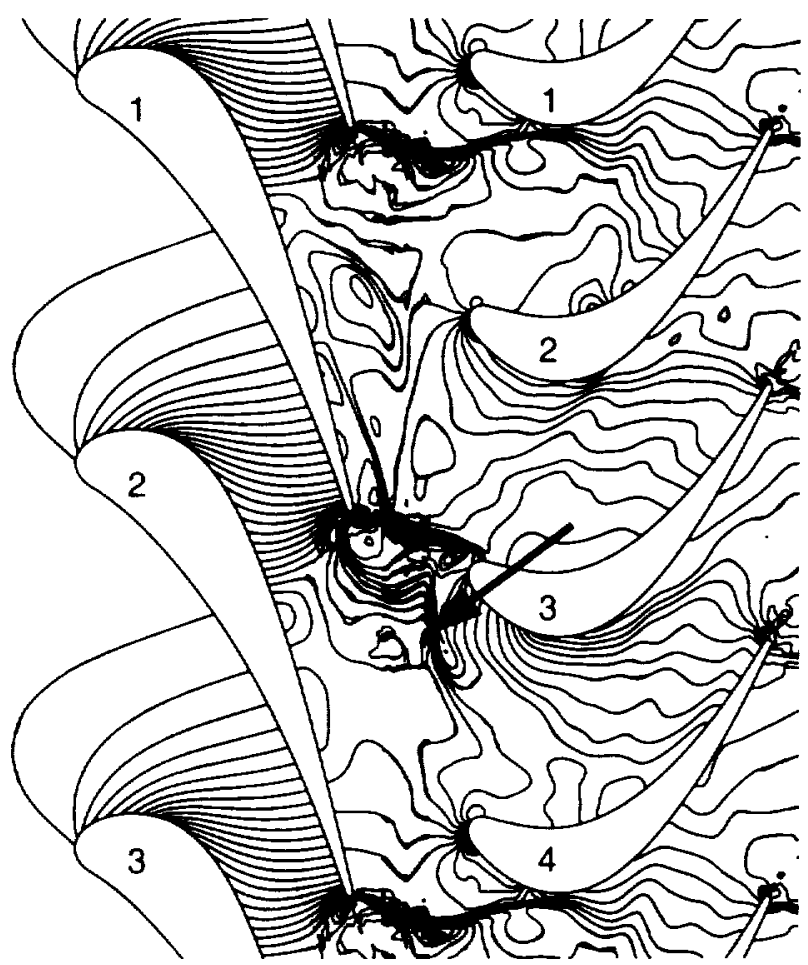

Figure 9. Instantaneous pressure contours in the flow for the reference design at $t=0.05$.

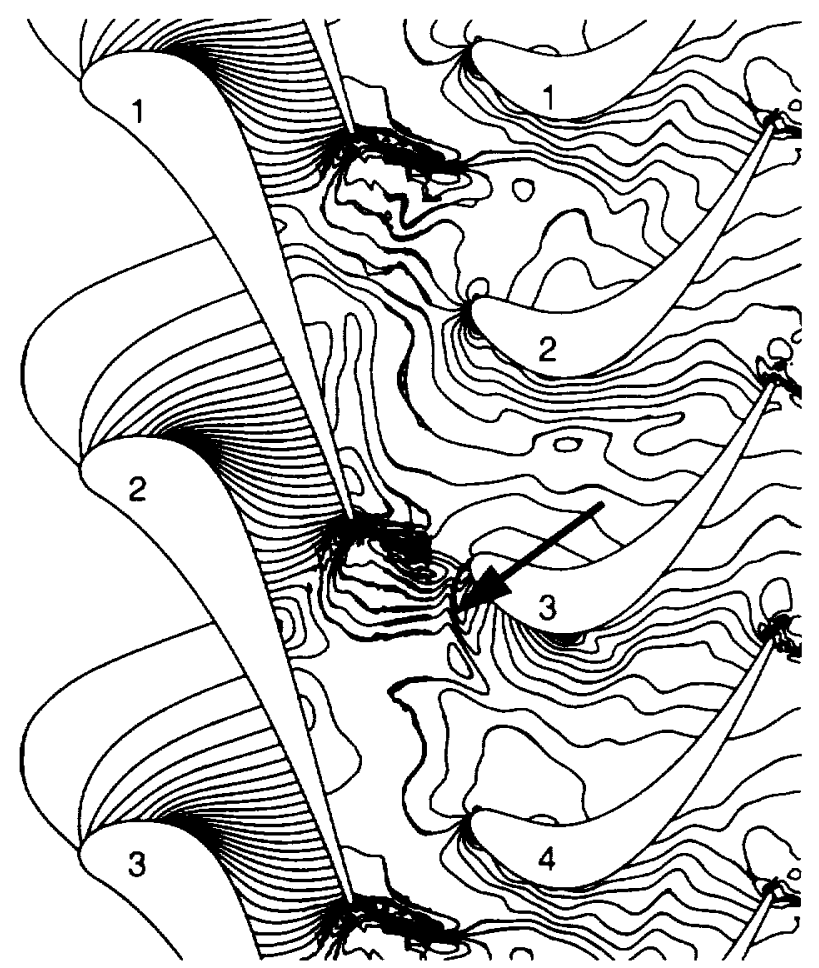

Figure 10. Instantaneous pressure contours in the flow for the optimized design at $t=0.0$.

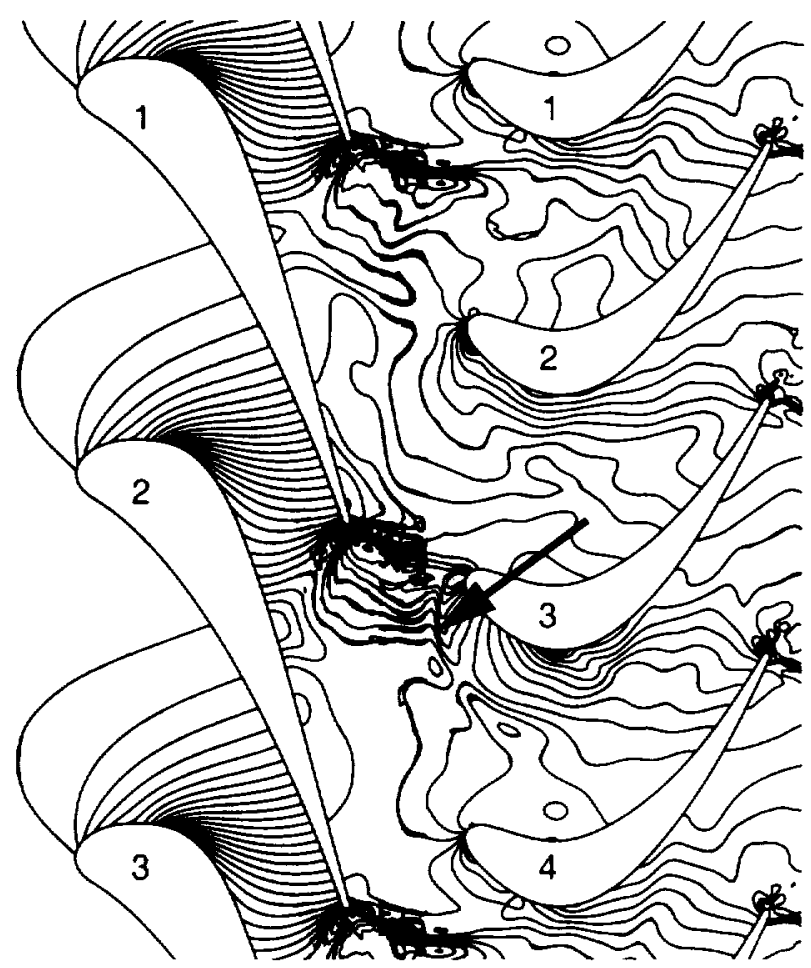

Figure 11. Instantaneous pressure contours in the flow for the optimized design at $t=0.05$. 


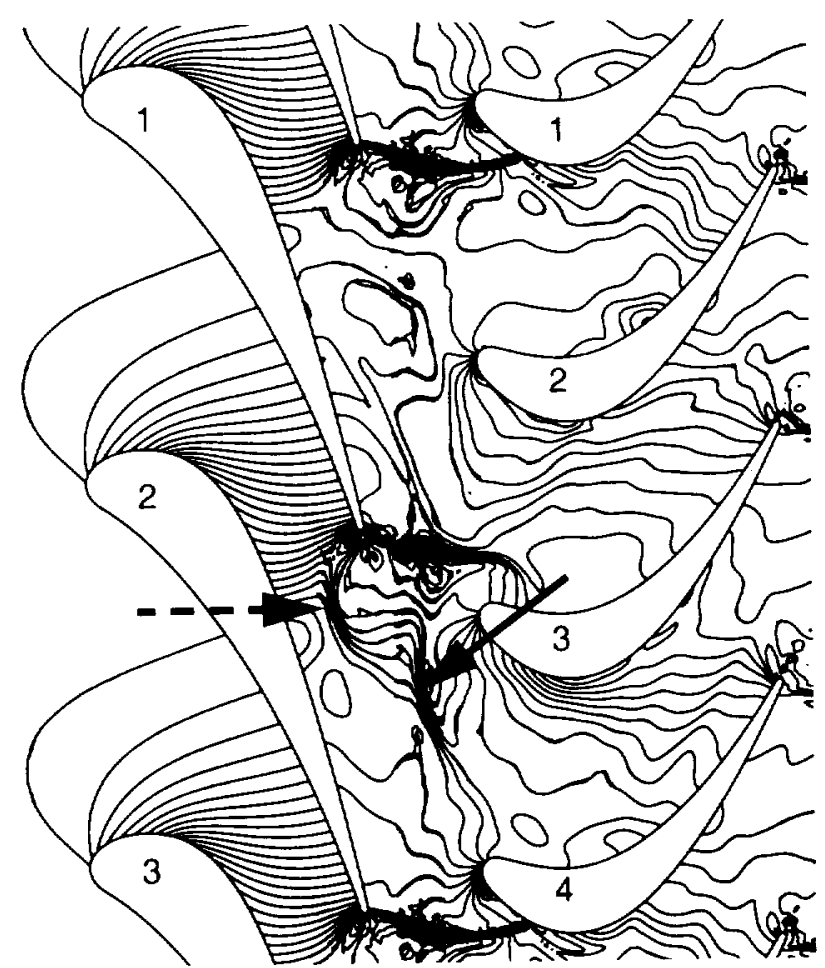

Figure 12. Instantaneous pressure contours in the flow for the reference design at $t=0.15$.

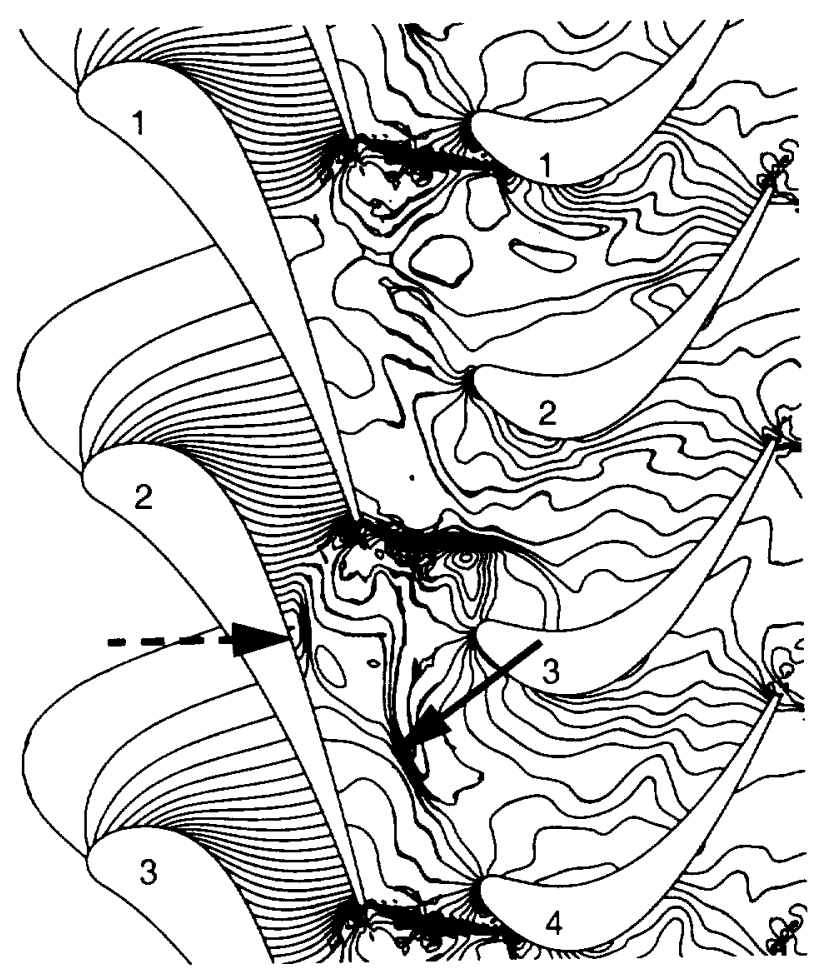

Figure 13. Instantaneous pressure contours in the flow for the reference design at $t=0.25$.

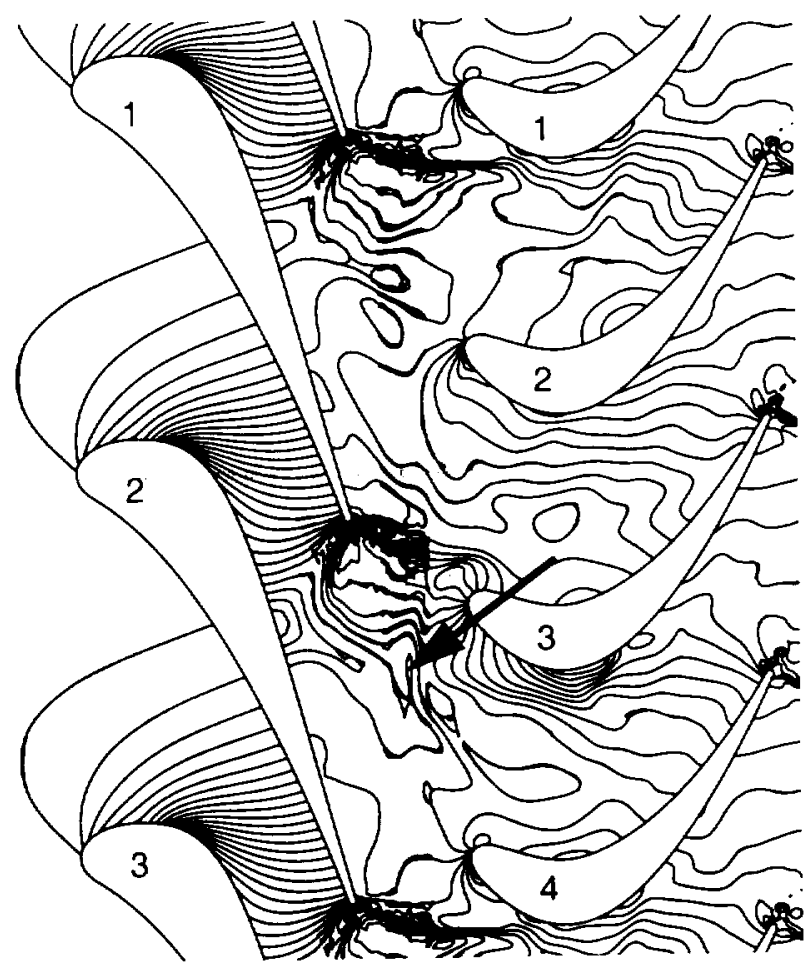

Figure 14. Instantaneous pressure contours in the flow for the optimized design at $t=0.15$.

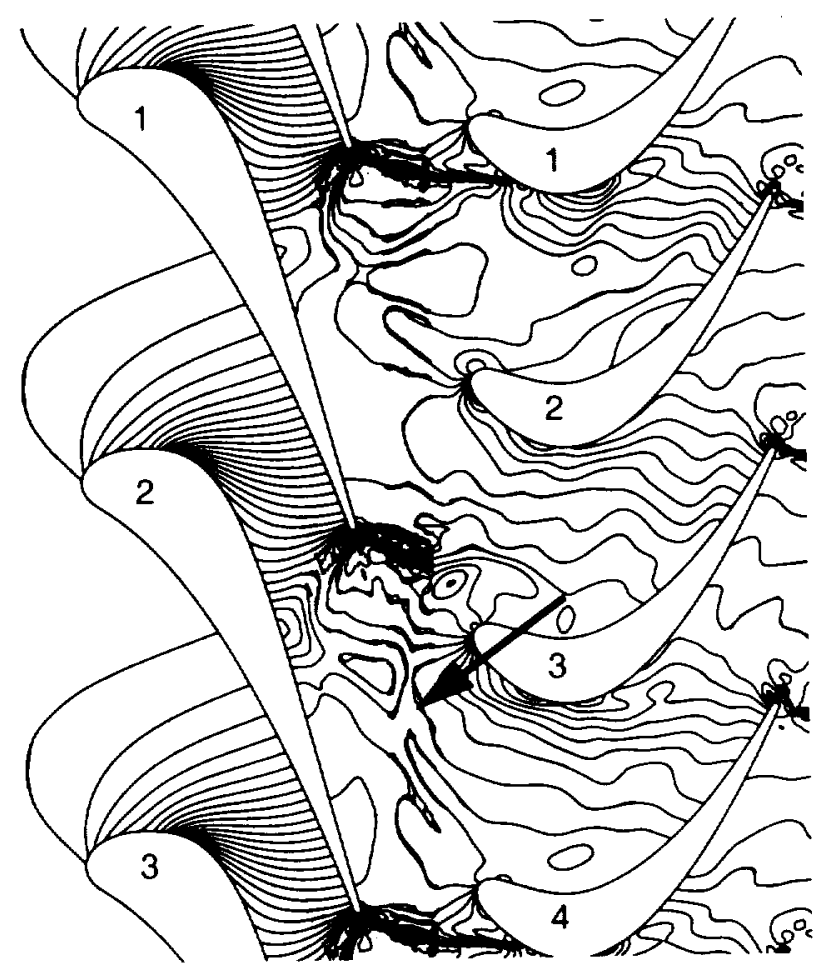

Figure 15. Instantaneous pressure contours in the flow for the optimized design at $t=0.25$. 


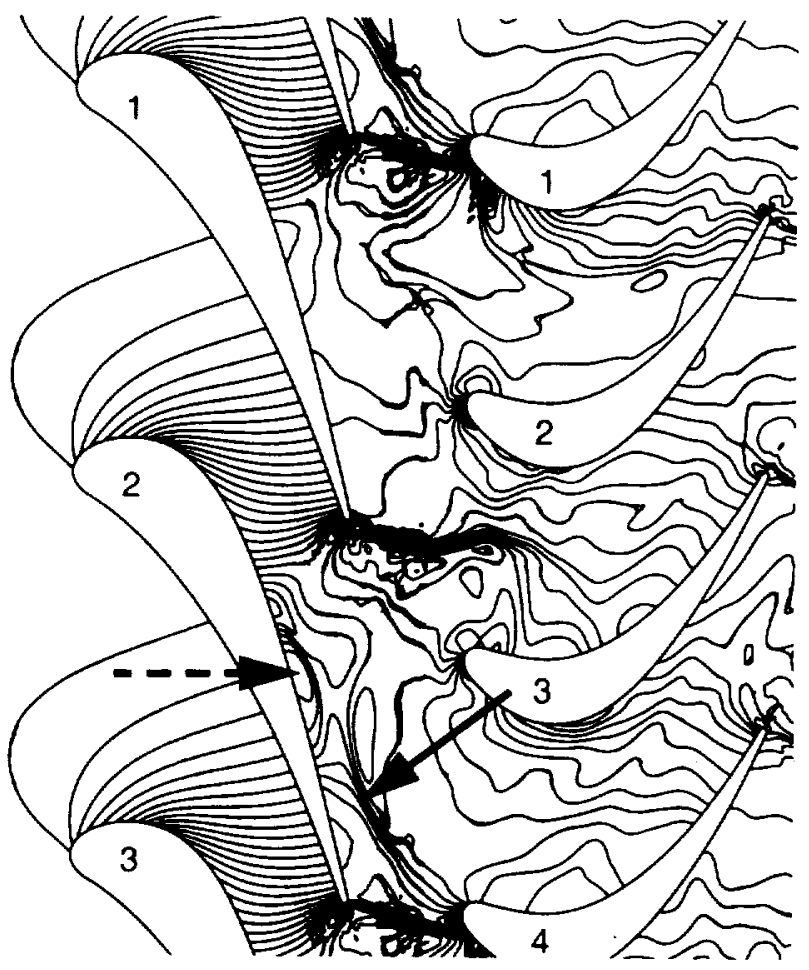

Figure 16. Instantaneous pressure contours in the flow for the reference design at $t=0.35$.

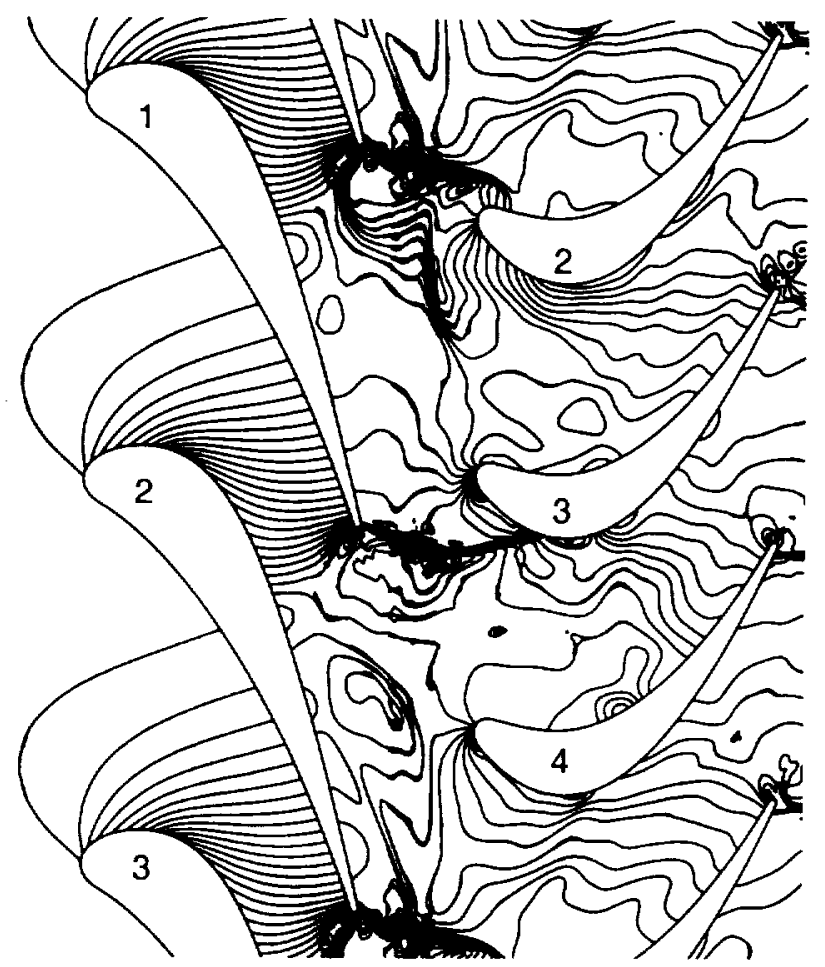

Figure 17. Instantaneous pressure contours in the flow for the reference design at $t=0.65$.

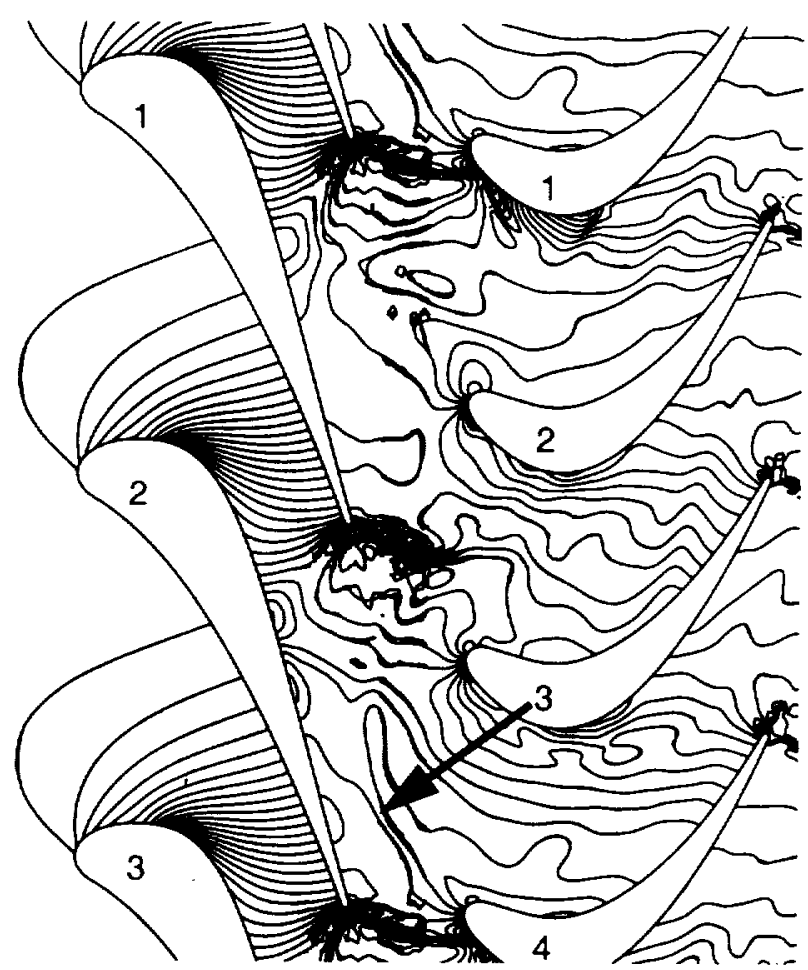

Figure 18. Instantaneous pressure contours in the flow for the optimized design at $t=0.35$.

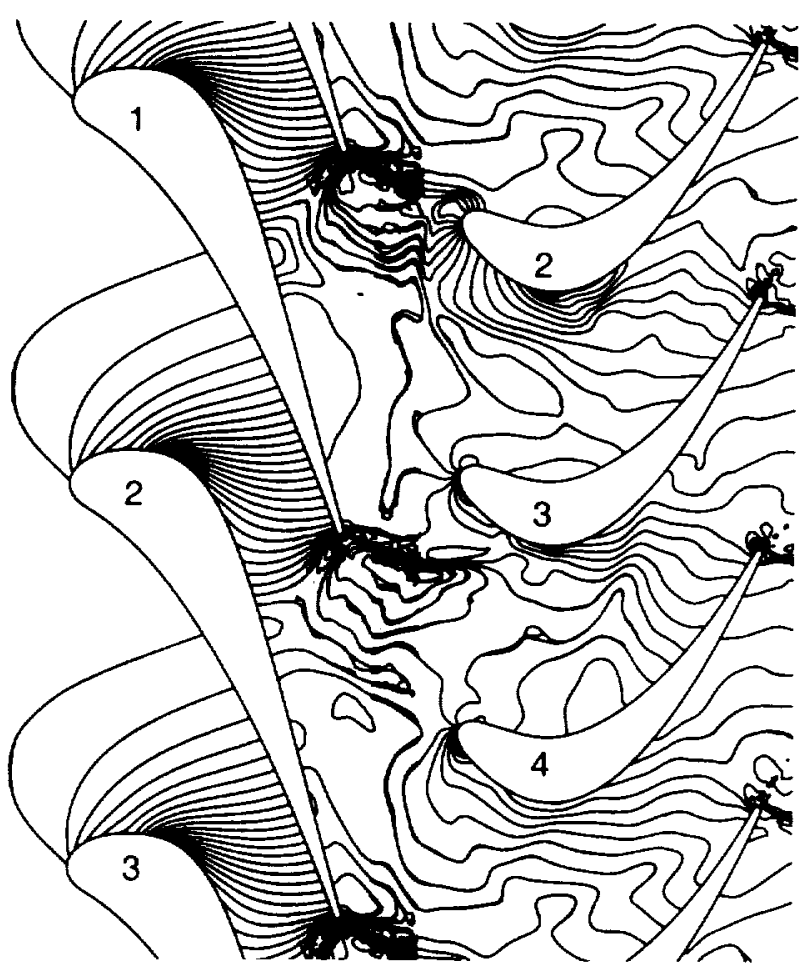

Figure 19. Instantaneous pressure contours in the flow for the optimized design at $t=0.65$. 


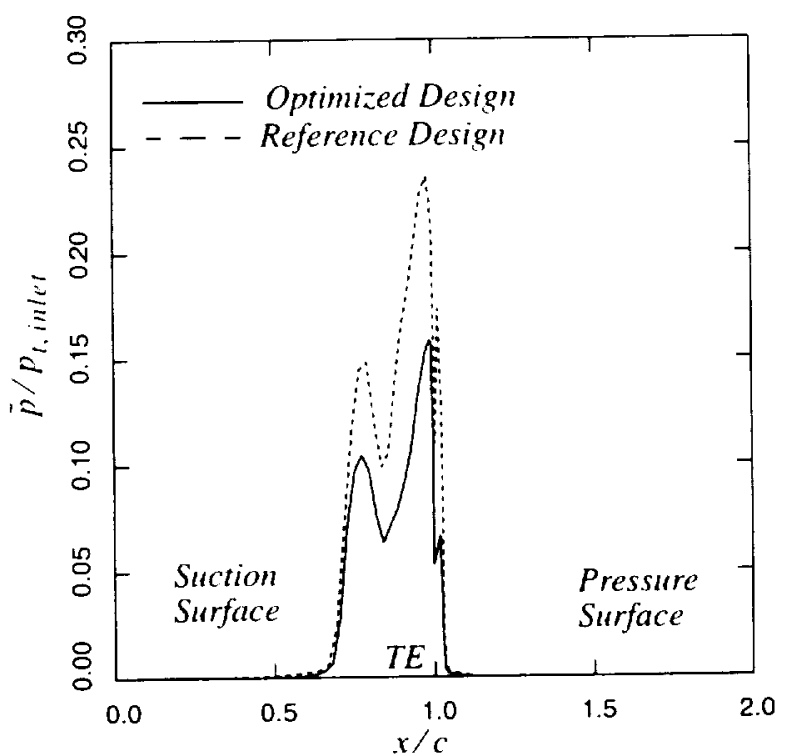

Figure 20. Comparison of the pressure amplitude distributions on the stator airfoils for the reference and optimized designs. TE denotes the trailing edge of the stator airfoil.

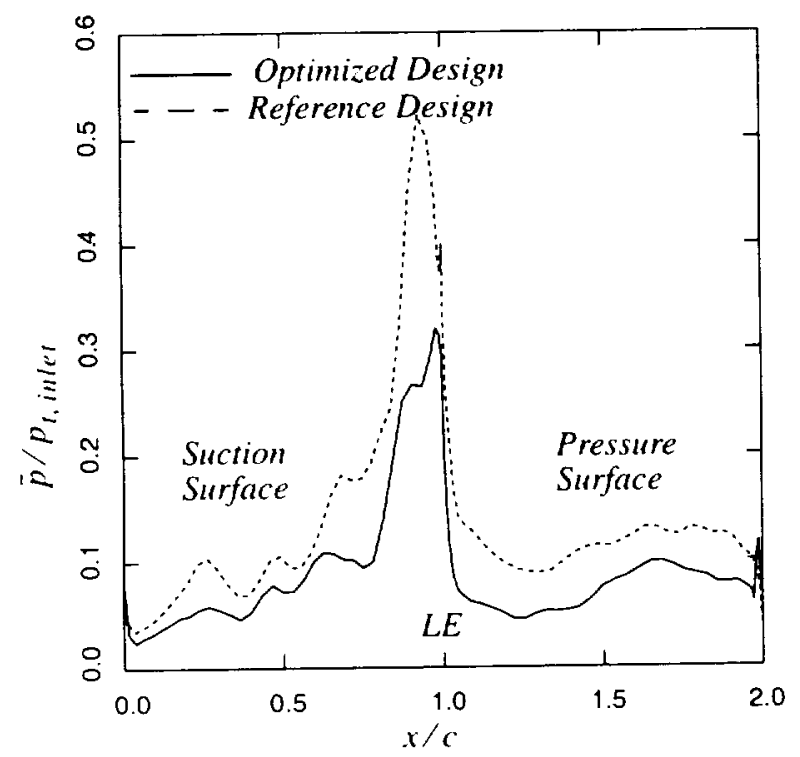

Figure 21. Comparison of the pressure amplitude distributions on the rotor airfoils for the reference and optimized designs. $L E$ denotes the leading edge of the rotor airfoil.
Figure $2 \mathrm{l}$ shows that shape optimization of the airfoils leads to a reduction in peak amplitude of about $40 \%$. The reduction of unsteady effects in the optimized design is due primarily to the weakening of the upper stator trailing edge shock. The unsteadiness due to potential and wake/blade interactions between the stator and rotor airfoils continues to be present since the axial gap between the stator and rotor airfoils was not changed in the optimization process. The peak amplitude for the optimized design is 0.32 .

\section{Boundary Layer Separation on Rotor Suction Surface}

Giles (ref. 5) notes that the unsteady shocks that interact with the rotor airfoils cause temporary leading edge separation on the rotor suction surface. Figure 22 shows the minimum value of the axial velocity (over a cycle) one grid point away from the rotor surface for the reference and optimized designs.

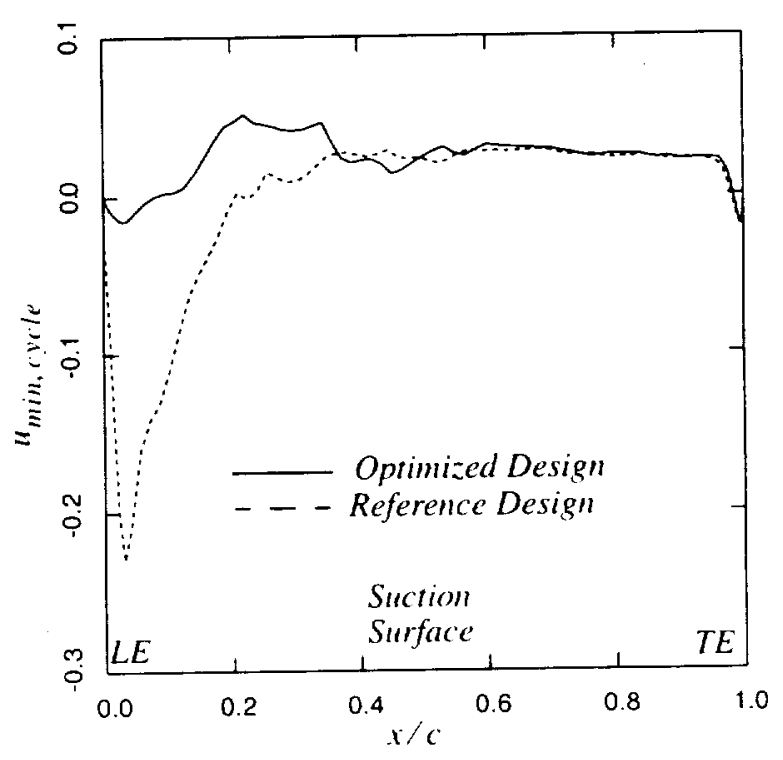

Figure 22. Comparison of the minimum axial velocity one grid point away from the rotor airfoil suction surface for the reference and optimized designs. 
Figure 22 clearly shows temporary leading edge boundary layer separation $(u<0.0)$ on the suction surface for the reference design as in Giles (ref. 5). This suction side flow separation is nearly eliminated in the optimized design. This demonstrates that the optimization process yielded better flow quality in the vicinity of the rotor leading edge on the suction surface

\section{Assessment of Optimized Turbine Design}

The main objective of this paper is to demonstrate that a systematic application of an aerodynamic design optimization method to a transonic turbine can enhance its unsteady aerodynamic performance. The instantaneous pressure contours shown in figures 8 through 19 , the airfoil surface pressure amplitude distributions shown in figures 20 and 21 , and the streamwise velocity variation at the rotor airfoil surface shown in figure 22 indicate the improvement in aerodynamic performance obtained by shape optimization of the airfoils. The reductions in unsteady pressure amplitudes were obtained without decreasing the tangential force on the rotor airfoils or the work output of the turbine. The flow angles and Mach numbers at the exit to the stator and rotor are nearly the same in the reference and optimized designs. Table 2 summarizes the uncooled stage efficiency and the inlet, midgap, and exit flow conditions for the reference and optimized designs.

The uncooled stage efficiency of the optimized design was nearly identical to that of the reference design. One would expect an increase in efficiency because of the weaker upper stator trailing edge shock in the optimized design. However, the fact that the efficiency is unchanged is not surprising because the stator exit Mach number is about 1.12. which is very close to unity, and the upper stator trailing edge shock is weak even in the reference design. It is possible that the optimization process could lead to designs with significantly improved efficiency or work output when applied to lurbine configurations with higher operating Mach numbers.

\begin{tabular}{|l|c|c|}
\hline \multicolumn{1}{|c|}{ Parameter } & $\begin{array}{c}\text { Refer- } \\
\text { ence } \\
\text { Design }\end{array}$ & $\begin{array}{c}\text { Opt1- } \\
\text { mized } \\
\text { Design }\end{array}$ \\
\hline Stator inflow angle & $0.0^{\circ}$ & $0.0^{\circ}$ \\
\hline Stator outflow angle & $-74.14^{\circ}$ & $-74.31^{\circ}$ \\
\hline $\begin{array}{l}\text { Stator inflow Mach number } \\
\text { Stator outtlow Mach num- } \\
\text { ber }\end{array}$ & 0.151 & 0.150 \\
\hline Rotor-relative inflow angle & $-45.11^{\circ}$ & $-44.57^{\circ}$ \\
\hline $\begin{array}{l}\text { Rotor-relative outflow angle } \\
\text { Rotor-relative inflow Mach } \\
\text { number }\end{array}$ & $60.91^{\circ}$ & $60.93^{\circ}$ \\
\hline $\begin{array}{l}\text { Rotor-relative outflow } \\
\text { Mach number }\end{array}$ & 1.018 & 0.441 \\
\hline Uncooled stage efficiency & 0.9489 & 0.9490 \\
\hline
\end{tabular}

TABLE 2. Comparison of flow parameters for the reference and optimized designs. All angles are measured from the axial direction.

\section{Concluding Remarks}

This paper demonstrates that a systematic application of a new aerodynamic design optimization method to a transonic turbine can enhance the turbine's unsteady aerodynamic performance without increasing its size or reducing its efficiency and work output. The design method used incorporates the advantages of both traditional RSM and neural networks. It employs a strategy called parameterbased partitioning of the design space and uses a sequence of response surfaces based on both neural networks and polynomials to traverse the design space in search of the optimal solution. This approach results in response surfaces that have both the power of neural networks and the economy of low-order polynomials (in terms of number of simulations needed and network training requirements). The proximity of the rotor and stator rows and impingement of the stator trailing edge shocks on the rotor airfoils results in strong rotor-stator interaction effects. Hence the use of a simulation code that can accurately compute unsteady flow in a turbine stage was necessary for the redesign effort. 
The application of this design method to a tran sonic turbine yielded a new design with a slightly different geometry. Results shown in this paper indicate that the unsteady stator trailing edge shock in the reference design has been weakened in the optimized design. This leads to lower unsteady pressure amplitudes on the airfoil surfaces and improved aerodynamic performance. These reductions in unsteady pressure amplitudes were obtained without decreasing the tangential force on the rotor airfoils or the work output of the turbine. The uncooled stage efficiency for the optimized design was nearly identical to that for the reference design. These results demonstrate the capabilities of the neural net-based design method in an unsteady flow environment.

The results presented in this paper add to the successful application of the neural net-based method to design in a steady flow environment (ref. 10,11) and demonstrate the versatility of the method. While we have used specific design problems as examples to illustrate the strengths of the method, it is becoming increasingly evident that the method can be applied to a wide range of turbomachinery and other general design problems.

\section{References}

1. Jennions, 1. K.; and Adamczyk, J. J.: Evaluation of the Interaction Losses in a Transonic Turbine HP Rotor/LP Vane Configuration, ASME Journal of Turbomachinery, vol. 119. 1997, pp. 68-76.

2. Sieverding, C. $\mathrm{H}$ : Experimental Data on Two Transonic Turbine Blade Sections and Comparison with Various Theoretical Methods, Transonic Flow's in Turbomachinery, VKI Lecture Series 59, Von Karman Institute, RhodeSt.-Genese, Belgium, 1973.

3. Ashworth, D. A.; LaGraff, J. E.; Schultz, D. L.; and Grindod, K. J.: Unsteady Aerodynamic and Heat Transfer Processes in a Transonic Turbine Stage. Joumal of Engineering for Gas Turbines and Power, vol. 107, 1985, pp. 10221030.

4. Guennette, G. R.; Epstein. A. H.; Giles, M. B.; Haimes, R.; and Norton. R. J. G.: Fully Scaled Transonic Turbine Rotor Heat Transfer Mea- surements, ASME Journal of Turbomachinery, vol. 111. 1989, pp. 1-7.

5. Giles, M. B.: Stator/Rotor Interaction in a Transonic Turbine. AIAA Journal of Propulsion and Power, vol. 6, 1990, pp. 621-633.

6. Abhari, R. S.; Guenette, G. R.; Epstein, A. H.; and Giles, M. B.: Comparison of TimeResolved Turbine Rotor Blade Heat Transfer Measurements and Numerical Calculations. ASME Journal of Turbomachinery, vol. 114, 1992, pp. 818-827.

7. Rangwalla, A. A.; Madavan. N. K.; and Johnson, P. D.: Application of an Unsteady Navier-Stokes Solver to Transonic Turbine Design. AIAA Journal of Propulsion and Power, vol. 8, no. 5, 1992, pp. 1079-1086..

8. Rangwalla, A. A.: Unsteady Navier-Stokes Computations for Advanced Transonic Turbine Design. AIAA Paper No. 94-2835, 30th AIAA/ASME/SAE/ASEE Joint Propulsion Conference, Indianapolis. IN, June 1994.

9. Madavan, N. K.; Rai, M. M.; and Huber, F. W.: Neural Net-Based Redesign of a Gas Generator Turbine for Improved Unsteady Aerodynamic Performance, AIAA Paper No. 99-2522. 35th AIAA/ASME/SAE/ASEE Joint Propulsion Conference and Exhibit, Los Angeles, CA, June 1999.

10. Rai, M. M.; and Madavan, N. K.: Application of Artificial Neural Networks to the Design of Turbomachinery Airfoils. AIAA Paper No. 981003, AIAA 36th Aerospace Sciences Meeting, Reno, NV, January 1998.

11. Rai, M. M.; and Madavan, N. K.: Aerodynamic Design Using Neural Networks. AIAA Paper No. 98-4928, 7th AIAA/USAF/NASA/ISSMO Symposium on Multidisciplinary Analysis and Optimization, St. Louis, MO, September 1998.

12. Johnson, P. D.; and Huber, F. W.: GGGT Preliminary Design. United Technologies Pratt and Whitney Memo Pass 57, West Palm Beach, FL, 1990.

13. Rai, M. M.; and Madavan. N. K.: Multi-Airfoil Navier-Stokes Simulations of Turbine RotorStator Interaction. ASME Journal of Turbomachinery vol. 112, 1990, pp. 167-190. 
14. Rao. K. V.: and Delaney, R. A.: Investigation of Unsteady Flow Through a Transonic Turbine Stage: Part I-Analysis, AIAA Paper No. 90-2409, 26th AIAA/ASME/SAE/ASEE Joint Propulsion Conference and Exhibit, Orlando, FL, July 1990.

15. Dunn, M.; Bennett, W.; Delaney, R. A.; and Rao. K. V.: Investigation of Unsteady Flow Through a Transonic Turbine Stage: Part IIData/Prediction Comparison for Time-Averaged and Phase-Resolved Pressure Data, AIAA Paper No. 90-2409, 26th AIAA/ASME/ SAE/ASEE Joint Propulsion Conference and Exhibit, Orlando, FL, July 1990.

16. Montgomery, D. C.: Design and Analysis of Experiments. John Wiley and Sons, New York, 1997.

17. Myers, R. H.; and Montgomery, D. C.: Response Surface Methodology-Process and Product Optimization Using Designed Experiments. John Wiley and Sons, New York, 1995. 

Pubiic reporting burden for this collection of intormation is estimated to average 1 hour per response, including the time for reviewing instructions, searching existing dala sources. gathering and maintaining the data needed, and completing and reviewing the collection of information. Send comments regarding inis burden estimate or any other aspect of this collection of Davis Highway, Suile 1204. Arlington. VA 22202-4302. and to the Office of Management and Budget, Paperwork Reduction Project (0704-0188), Washington, OC 20503.

\begin{tabular}{|l|l|l}
\hline 1. AGENCY USE ONLY (Leave blank) & $\begin{array}{c}\text { 2. REPORT DATE } \\
\text { September } 1999\end{array}$ & $\begin{array}{c}\text { 3. REPORT TYPE AND DATES COVERED } \\
\text { Technical Memorandum }\end{array}$
\end{tabular}

\begin{tabular}{l|l} 
4. TITLE AND SUBTITLE & 5. FUNDING NUMBERS
\end{tabular}

Improving the Unsteady Aerodynamic Performance

of Transonic Turbines Using Neural Networks

6. AUTHOR(S)

Man Mohan Rai, Nateri K. Madavan, and Frank W. Huber*

7. PERForming organization NAME(S) AND AddRESS(ES)

8. PERFORMING ORGANIZATION REPORT NUMBER

Ames Research Center

Moffett Field, CA 94035-1000

A-99V0041

9. SPONSORING/MONITORING AGENCY NAME(S) AND ADDRESS(ES)

10. SPONSORING/MONITORING AGENCY REPORT NUMBER

National Aeronautics and Space Administration

Washington, DC 20546-0001

NASA/TM-1999-208791

11. SUPPLEMENTARY NOTES

Point of Contact: Nateri K. Madavan, Ames Research Center, MS T27A-1, Moffett Field, CA 94035-1000 (650) 604-4427

*Riverbend Design Services, Palm Beach Gardens, FL.

12a. DISTRIBUTION/AVAILABILITY STATEMENT

12b. DISTRIBUTION CODE

Unclassified - Unlimited

Subject Category 02

Availability: NASA CASI (301) 621-0390

Distribution: Standard

13. ABSTRACT (Maximum 200 words)

A recently developed neural net-based aerodynamic design procedure is used in the redesign of a transonic turbine stage to improve its unsteady aerodynamic performance. The redesign procedure used incorporates the advantages of both traditional response surface methodology and neural networks by employing a strategy called parameter-based partitioning of the design space. Starting from the reference design, a sequence of response surfaces based on both neural networks and polynomial fits are constructed to traverse the design space in search of an optimal solution that exhibits improved unsteady performance. The procedure combines the power of neural networks and the economy of low-order polynomials (in terms of number of simulations required and network training requirements). A time-accurate, two-dimensional, Navier-Stokes solver is used to evaluate the various intermediate designs and provide inputs to the optimization procedure. The procedure yielded a modified design that improves the aerodynamic performance through small changes to the reference design geometry. These results demonstrate the capabilities of the neural net-based design procedure, and also show the advantages of including high-fidelity unsteady simulations that capture the relevant flow physics in the design optimization process.

\section{SUBJECT TERMS}

Neural networks, Transonic turbines, Aerodynamic performance

15. NUMBER OF PAGES

23

16. PRICE CODE

$\mathrm{A03}$

\begin{tabular}{l|l} 
17. SECURITY CLASSIFICATION \\
OF REPORT \\
Unclassified
\end{tabular}$\quad \begin{aligned} & \text { 18. SECURITY CLASSIFICATION } \\
& \text { OF THIS PAGE } \\
& \text { Unclassified }\end{aligned}$

19. SECUAITY CLASSIFICATION OF ABSTRACT 

